\title{
Penerapan School Based Vector Control (SBVC) untuk Pencegahan dan Pengendalian Vektor Penyakit di Sekolah
}

\section{Implementation of School Based Vector Control (SBVC) to Prevent and Vector Control Diseases in School}

\author{
Nur Siyam*, Widya Hary Cahyati \\ Universitas Negeri Semarang, Departemen Epidemiologi dan Biostatistik, Jurusan Ilmu \\ Kesehatan Masyarakat, Fakultas Ilmu Keolahragaan \\ (nursiyam@mail.unnes.ac.id)
}

\begin{abstract}
ABSTRAK
Upaya mewujudkan sekolah sehat bebas vektor perlu ditingkatkan, karena semakin banyaknya penyakit menular akibat vektor seperti scabies, dermatitis, Diare, thypoid, serta DBD pada siswa. Langkah yang bisa diambil untuk membangun Perilaku Hidup Bersih dan Sehat (PHBS) dalam mencegah dan mengendalikan perkembangbiakan vektor penyakit salah satunya dengan menerapkan School Based Vector Control (SBVC) di sekolah. Penerapan SBVC ini menekankan pada kesadaran dan kepedulian siswa dalam pengendalian dan penciptaan lingkungan sehat. Tujuan penelitian adalah terbentuknya model SBVC dan mendapatkan gambaran efektifitas model SBVC sebagai upaya peningkatan PHBS dan penciptaan lingkungan sehat pada siswa. Penelitian di lakukan di SMP Islam Sultan Agung 4, Semarang. Populasi penelitian adalah seluruh siswa SMP Islam Sultan Agung 4 Semarang. Sampel adalah siswa yang mempunyai permasalahan kesehatan dan kebiasaan tidak sehat sebanyak 30 siswa. Jenis penelitian adalah Kuasi Eksperimen dengan rancangan Non Randomized One Group Pretest- Posttest Design. Pengumpulan data dilakukan dengan observasi, wawancara, dan pengisian kuesioner. Instrument penelitian, checklist observasi, dan kuesioner. Analisis data univariat dan bivariat dengan uji statistik wilcoxon. Hasil penelitian menunjukkan indikator kebersihan perorangan, kebersihan di dalam kelas, kebersihan di jamban dan tempat wudhu, dan kebersihan di halaman sekolah antara sebelum dan setelah diterapkan SBVC meningkat secara signifikan $(\mathrm{p}<0,05)$. Sehingga perilaku hidup bersih dan sehat pada siswa dalam mencegah dan mengendalikan vektor di sekolah meningkat signifikan $(\mathrm{p}=0,00)$.
\end{abstract}

Kata kunci : Pencegahan, vektor, sekolah

\section{ABSTRACT}

Efforts to achieve a healthy school free vectors need to be improved because of the increasing number of vector-transmitted diseases such as scabies, dermatitis, diarrhoea, typhoid, and dengue in students. Steps that can be taken to establish a clean and healthy lifestyle in preventing and controlling the disease vector breeding either by implementing the School-Based Vector Control (SBVC) in school. Application of this SBVC emphasis on awareness and concern of students in the control and the creation of a healthy environment. The research objective is the establishment of a model SBVC and gets an idea of the effectiveness of the model SBVC as improving the PHBs and the creation of a healthy environment to the students. The research was done in SMP Islam Sultan Agung 4, Semarang. The study population was all students of SMP Islam Sultan Agung 4 Semarang. Samples are students who have health problems and unhealthy as many as 30 students. This type of research is a Quasi-Experiments with non-randomized design one group pretest-posttest design. The data collection is done by observation, interviews, and questionnaires. The instrument of research is observation checklists and questionnaires. Univariate and bivariate data analysis by Wilcoxon statistical test. The results showed indicators of personal hygiene, hygiene in the classroom, cleanliness in toilets and ablution and cleanliness in the schoolyard before and after application of $S B V C$ increased significantly $(p<0.05)$. So that a clean and healthy living behaviour in students in the prevention and control of vector at school increased significantly $(p=0.00)$.

Keywords : Prevention, vectors, school 


\section{PENDAHULUAN}

Lingkungan sekolah sehat, akan mendukung pencapaian tujuan pendidikanSalah satu upaya pencapaian tujuan pendidikan adalah pelaksanaan program UKS. Tiga program pokok UKS, yaitu pendidikan kesehatan, pelayanan kesehatan, dan pembinaan lingkungan sehat perlu didorong dan dimasyarakatkan agar semua pihak memahami dan mendukung program ini di sekolah. Selain itu, pentingnya mengajak siswa dan memberikan kesadaran kepada mereka akan pentingnya menanamkan perilaku hidup sehat dan bersih dalam menciptakan lingkungan sekolah yang sehat. ${ }^{1}$

Pendidikan kesehatan dan upaya pencegahan dan pengendalian penyakit di sekolah masih perlu dilakukan. Hal ini dikarenakan masih kurangnya kesadaran siswa dalam berperilaku hidup bersih dan sehat serta kurang menjaga lingkungan sekolah. Penelitian yang dilakukan oleh Kusuma menyebutkan bahwa perilaku hidup bersih dan sehat masih dalam kategori kurang, padahal kebiasaan ini akan mempengaruhi kesehatan siswa di sekolah. ${ }^{2}$ Berdasarkan data dari Litbangkes Ponorogo tahun 2003-2004, jenis penyakit yang muncul akibat hygiene individu dan sanitasi lingkungan yang kurang adalah scabies (39,5\%), Dermatitis $(18,2 \%)$, ISPA $(18,5 \%)$, Diare $(11,2 \%)$, Typhus $(1,6 \%)$, Gastritis $(7,3 \%)$, dan allergi $(3,8 \%){ }^{3}$

Beberapa kebiasaan anak yang bisa memengaruhi perilaku kesehatan di sekolah yaitu pola sarapan anak, kebiasaan mencuci tangan, kebersihan telinga, kebersihan kulit, kebersihan kuku, kebersihan pakaian, kebersihan rambut, mandi dan juga kebiasaan anak-anak untuk jajan di tempat sembarangan dengan jajanan yang rata-rata tidak sehat, selain itu juga kebiasaan membuang sampah tidak di tempatnya. Usia anak SMP merupakan usia anak remaja yang membutuhkan bimbingan yang tepat agar mereka tidak salah dalam menemukan jati diri. Oleh karena itu, para remaja perlu dibekali dengan pengetahuan dan keterampilan tentang kesehatan, agar remaja lebih bertanggungjawab terhadap kehidupan reproduksi maupun kehidupan di lingkungannya. ${ }^{4-6}$

Perilaku kesehatan merupakan respon seseorang terhadap stimulus berkaitan dengan sakit dan penyakit, sistem pelayanan kesehatan, makanan minuman serta lingkungan. ${ }^{7}$

Berdasarkan hasil wawancara peneliti den- gan pihak sekolah, menerangkan bahwa masalah kesehatan terkait penyakit menular seperti dermatitis, pediculosis, panu, scabies, adalah penyakit yang sudah menjadi langganan di lingkungan sekolah dan sekitar sekolah. Selain itu, kebiasaan siswa yang membuang sampah di sembarang tempat menyebabkan sampah/ bungkus makanan berserakan di halaman sekolah, di taman, bahkan masuk ke dalam saluran air/got. Sampah dan sisa-sisa makanan tidak jarang ditemukan di dalam laci meja mereka.

Membangun perilaku hidup bersih dan sehat dalam mencegah dan mengendalikan perkembangbiakan vektor penyakit salah satunya adalah dengan menerapkan metode School Based Vector Control (SBVC) di sekolah. ${ }^{8}$ Inti penerapan SBVC ini adalah pengendalian vektor berbasis sekolah. Partisipasi seluruh warga sekolah dalam kegiatan penciptaan lingkungan yang sehat bebas vektor bertujuan agar mereka mau dan mampu untuk hidup bersih dan sehat. Konsep SBVC ini untuk memberikan pendidikan vektor penyakit, menemukan perilaku yang tidak bersih dan sehat, menemukan penyebab sanitasi lingkungan yang buruk agar mereka mampu berkomunikasi dan mengupayakan penyelesaian permasalahan yang mereka hadapi melalui kerjasama di dalam tim dan dengan pengurus sekolah tersebut. Tujuan penelitian adalah terbentuknya model SBVC dan mendapatkan gambaran efektifitas model SBVC sebagai upaya peningkatan PHBS dan penciptaan lingkungan sehat pada siswa.

\section{BAHAN DAN METODE}

Penelitian di lakukan di SMP Islam Sultan Agung 4, Kecamatan Genuk, Kota Semarang, Kota Semarang. Penelitian dilakukan pada tahun 2016 selama kurang lebih 8 bulan. Populasi dalam penelitian ini adalah seluruh warga di SMP Islam Seltan Agung 4, Kecamatan Genuk, Kota Semarang. Sampel penelitian adalah siswa yang mempunyai permasalahan kesehatan dan mempunyai kebiasaan tidak sehat berdasarkan hasil koordinasi dari guru wali kelas, dan sebagian lagi siswa berprestasi yang dapat menjadi leader dalam kelompok. Penelitian ini adalah Quasi Experiment dengan rancangan Non Randomized One Group Pretest- Posttest Design.

Instrument penelitian adalah checklist ob- 
servasi, pedoman wawancara dan kuesioner. Analisis data menggunakan analisis univariabel, data hasil penelitian dideskripsikan dalam bentuk tabel, grafik, dan narasi) dan analisis bivariabel digunakan untuk mengetahui efektifitas metode yaitu sebelum dan setelah penerapan metode menggunakan uji statistik Wilcoxon.

\section{HASIL}

Hasil wawancara dengan pihak sekolah menyebutkan masalah kesehatan yang terjadi pada siswa adalah penyakit dermatitis (gatal pada kulit), scabies, selain itu, juga penyakit DBD. Keadaan kebersihan diri setiap siswa masih kurang, misalnya jarang mengganti pakaian, membuang sampah di selokan, membuang sampah di laci meja kelas, membuang sampah di pekarangan sekolah. Keadaan kebersihan lingkungan disekitar sekolah adalah di kelilingi oleh got, air rob sering menggenang setiap pukul 14.00-15.00 WIB.

Tersedianya kantin di sekolah yang menjajakan makanan siap saji maupun makanan yang diolah terlebih dahulu. Kantin di sekolah perlu mendapatkan perhatian karena dapat menjadi tempat perkembangbiakan vektor jika kebersihan dan cara penyimpanan bahan makanannya tidak dijaga

Tabel 1. Hasil Identifikasi Perilaku Berisiko Menimbulkan tempat perkembangbiakan Vektor di Sekolah

\begin{tabular}{clc}
\hline No. & \multicolumn{1}{c}{ Masalah PHBS } & \% \\
\hline A & Kebersihan Perorangan & \\
1 & Pakaian yang sudah dipakai, dipakai lagi sebelum dicuci & 43,3 \\
2 & Sisa makanan yg berserakan/tidak dibersihkan di lingkungan sekolah & 50,0 \\
3 & Membuang sampah di selokan & 60,0 \\
4 & Membuang sampah tidak di tempat sampah & 75,0 \\
5 & Menimbun sampah di dalam laci meja kelas & 80,0 \\
6 & Makan makanan tidak ditutup/ dihinggapi lalat & 26,7 \\
7 & Tidak mandi sebelum ke sekolah & 26,7 \\
8 & Jarang memotong dan membersihkan kuku & 23,3 \\
9 & Jarang mencuci rambut dengan sampo & 23,3 \\
& & \\
B & Kebersihan di dalam kelas & \\
1 & Tidak membuka jendela setiap hari & 86,7 \\
2 & Sepatu kotor dibiarkan masuk ke dalam kelas & 63,3 \\
3 & Lantai kelas jarang di pel & 53,3 \\
4 & Lantai kelas jarang di sapu & 50,0 \\
5 & Ada sampah berserakan di kelas & 80,0 \\
6 & Tidak menyediakan tempat sampah yang tertutup di dalam kelas & 78,0 \\
& & \\
C & Kebersihan jamban dan tempat wudhu & \\
1 & Sesudah BAB tidak cuci tangan dengan sabun & 26,7 \\
2 & WC tidak di siram sampai bersih & 30,0 \\
3 & Air limbah dibiarkan tidak mengalir kedalam got sehingga menjadi sarang nyamuk & 23,3 \\
4 & Kamar mandi berlumut dan licin & 16,7 \\
5 & Tempat wudhu berlumut dan licin & 13,3 \\
6 & Tidak menguras bak mandi secara rutin seminggu sekali & 23,3 \\
& & \\
D & Kebersihan Halaman Sekolah & 50,0 \\
1 & Disekitar/ lingkungan sekolah banyak batu, lumpur, dan rumput yang tinggi \\
2 & Saluran air di sekitar sekolah tersumbat oleh sampah & 23,3 \\
3 & Air tergenang di sekitar sekolah & 16,7 \\
4 & Sampah di lingkungan sekolah tidak dikelola dengan baik & 75,0 \\
5 & Halaman/ lingkungan sekolah jarang disapu/ dibersihkan & 23,3 \\
\hline
\end{tabular}

Sumber: Data Primer, 2016 
Tabel 2. Rata-rata skor PHBS dan Manajemen Lingkungan dalam Pengendalian Vektor

\begin{tabular}{|c|c|c|}
\hline No. & Kelompok & Rata-rata skor dalam 1 bulan (\%) \\
\hline 1 & Diponegoro & 83 \\
\hline 2 & Pattimura & 80 \\
\hline 3 & Kartini & 78 \\
\hline 4 & Bud Utomo & 74 \\
\hline \multirow[t]{2}{*}{5} & Ki Hajar Dewantara & 70 \\
\hline & Rata-rata & 77,2 \\
\hline
\end{tabular}

Sumber: Data Primer, 2016

Tabel 3. Hasil Pengolahan Data PHBS Dan Manajemen Lingkungan Sebelum dan Sesudah Penerapan SBVC untuk Pencegahan dan Pengendalian Vektor

\begin{tabular}{llccc}
\hline \multirow{2}{*}{ No. } & \multicolumn{1}{c}{ Variabel } & \multicolumn{2}{c}{ Penerapan ICCM } \\
\cline { 3 - 5 } & & $\begin{array}{c}\text { Rata-rata } \\
\text { sebelum }(\%)\end{array}$ & $\begin{array}{c}\text { Rata-rata } \\
\text { sesudah (\%) }\end{array}$ & delta \\
\hline 1 & PHBS di dalam kelas & 83,2 & $95,3 *$ & 12,1 \\
2 & PHBS di jamban dan tempat wudhu & 74,8 & $90,1 *$ & 15,3 \\
3 & PHBS individu & 73,0 & $83,9 *$ & 10,9 \\
4 & PHBS di halaman sekolah & 68,7 & $80,7 *$ & 10,5 \\
\hline Rata-rata PHBS Santri secara menyeluruh & $\mathbf{7 4 , 9 3}$ & $\mathbf{8 7 , 5}$ & $\mathbf{1 2 , 2}$ \\
\hline
\end{tabular}

*signifikan pada uji wilcoxon $(\alpha=0,05)$

Sumber: Data Primer, 2016

dengan baik. Intervensi khusus yang dilakukan untuk menyelesaikan masalah kesehatan yang terjadi belum ada. Kegiatan yang ada hanyalah pembentukan jadwal piket untuk membersihkan sekolah dan menyediakan petugas kebersihan di sekolah, sedangkan penyuluhan yang pernah dilakukan oleh puskesmas belum mengenai PHBS dan sanitasi lingkungan tetapi hanya menyangkut penyakit DBD.

Penelitian dilakukan pada siswa, pemilihan siswa didasarkan pada rekomendasi dari guru kelas. Siswa yang dipilih adalah mereka yang merupakan siswa berprestasi dan juga siswa yang menjaga kebersihan. Sedangkan untuk penyeimbang dalam memudahkan perubahan perilaku maka dipilih juga siswa yang kurang peduli dengan kebersihan lingkungan. Indikator yang diambil dalam penelitian ini berjumlah 7, yaitu: 1) Perilaku membuang sampah 2) Kebersihan tempat wudhu, 3) Kebersihan ruang belajar/ kelas, 4) Kebersihan halaman sekolah, 5) Keberadaan tempat sampah, 6) Bak penampungan air bebas jentik, 7) Kebersihan kantin sekolah. Indikator ini menjadi kunci penentu untuk melihat perubahan lingkungan setelah diterapkannya SBVC.

Tahap yang ke tiga dari SBVC adalah melaku- kan implementasi pengendalian vektor sesuai dengan kemampuan sekolah yang telah disepakati bersama, yaitu pembentukan tim pelaksana SBVC di sekolah. Tim ini terdiri dari 5 kelompok/ grup. Satu kelompok terdiri dari 1 orang ketua dan 5 orang anggota. Berikut adalah nama-nama kelompok tersebut; Kelompok Pattimura, Diponegoro, Kartini, Ki Hajar Dewantoro dan Budi Utomo. Hal ini dimaksudkan agar masing-masing kelompok mudah melalukan pemantauan PHBS dan manajemen lingkungan dalam upaya mengendalikan vektor di sekolah secara rutin. Pemantauan dilakukan setiap minggu selama 1 bulan. Masing-masing kelompok akan dihitung jumlah rata-rata skor perminggunya. Rata-rata skor PHBS dan Manajemen Lingkungan dalam Pengendalian Vektor di sekolah dapat dilihat pada Tabel 2.

Berdasarkan Tabel 1, tujuh masalah PHBS yang paling tinggi yang ada di sekolah berdasarkan kesepakatan bersama adalah membuang sampah di laci meja (90,0\%), membuang sampah dan sisa makanan di selokan $(86,7 \%)$, membuang sampah tidak di tempat sampah (di lingkungan sekolah) (80,0\%), sampah di lingkungan sekolah kurang dikelola dengan baik (63,3\%). Permasalahan yang telah ditemukan bersama-sama kemudian 
disepakati untuk diselesaikan bersama. Tahap selanjutnya adalah identifikasi pengendalian vektor sesuai dengan kemampuan sekolah.

Kelompok Diponegoro menduduki skor yang tertinggi karena sebagian besar kelompok Diponegoro beranggotakan anak OSIS. Mereka merupakan anak-anak yang berprestasi dan rajin. Kelompok Ki Hajar Dewantoro memperoleh sekor yang paling rendah karena kelompok ini mempunyai anggota kelompok yang kurang kompak karena kurang mendapat dukungan dari guru kelasnya. Rata-rata skor PHBS dan manajemen lingkungan dalam pengendalian vektor di sekolah setiap minggunya meningkat. PHBS di dalam kelas mempunyai delta yang paling tinggi karena kebersihan di dalam kelas menjadi prioritas permasalahan bagi siswa, sehingga mereka merasa harus diselesaikan. Ruang kelas yang nyaman akan membuat mereka betah dan nyaman dalam belajar.

Hasil analisis dengan uji wilcoxon menunjukkan bahwa semua variabel, yaitu PHBS individu, PHBS di dalam kelas, PHBS di jamban dan tempat wudhu, PHBS di halaman/ lingkungan sekitar sekolah sesudah menerapkan SBVC menunjukkan perubahan yang signifikan $(\mathrm{p}<0,05)$. PHBS siswa dapat dilihat pada Tabel 3 secara menyeluruh meningkat setelah di terapkan Metode SBVC.

\section{PEMBAHASAN}

Penerapan SBVC in menekankan pada pengendalian vektor berbasis sekolah. Seluruh warga sekolah terlibat dalam kegiatan penciptaan lingkungan yang sehat bebas vektor agar mau dan mampu untuk hidup bersih dan sehat. Konsep SBVC ini adalah melandaskan kegiatan sekolah untuk memberikan pendidikan vektor penyakit, menemukan perilaku yang tidak bersih dan sehat, menemukan penyebab sanitasi lingkungan yang buruk agar mereka mampu berkomunikasi dan mengupayakan penyelesaian permasalahan yang mereka hadapi melalui kerjasama di dalam tim dan dengan pengurus sekolah tersebut. ${ }^{9}$ Melalui SBVC ini diharapkan pengendalian vektor penyakit dapat berkelanjutan/ sustainable. Sehingga pada akhirnya kesadaran dan kepedulian akan pentingnya hidup bersih dan sehat dan lingkungan sehat dapat tumbuh dengan baik. ${ }^{8}$

Instansi seperti sekolah merupakan tempat yang berpotensi menjadi habitat perkembangan vektor penyakit. Kantin sekolah yang kurang mendapatkan perhatian dapat menjadi penyebab datangnya vektor, termasuk sampah yang harus selalu dikelola dengan baik. Pengendalian vektor dapat dilakukan dengan metode tunggal ataupun pengendalian vektor terpadu. Pengendalian vektor dapat dilakukan secara biologi, kimiawi, fisik/ mekanik, rekayasa genetik untuk vektor maupun melalui manajemen lingkungan. ${ }^{10-13}$ Pengendalian vektor disekolah seharusnya diikuti dengan pelibatan semua unsure penghuninya yang menjadi subjek pelaksana pengendalian vector, yaitu guru, siswa dan penjaja makanan di kantin. pengendalian vektor yang melibatkan peran semua pihak termasuk stake holder di sekolah akan membuat program dapat sustainable. ${ }^{14}$

Kemauan untuk melakukan tindakan pencegahan dan pengendalian vektor yang didukung dengan koordinasi yang intensif akan menghasilkan perilaku yang dapat bertahan lama, sehingga dapat menjadi kebiasaan ${ }^{15}$ Penelitian yang dilakukan di Malaysia tentang aktivitas pengendalian nyamuk Aedes aegypty menyebutkan bahwa sebagian besar biaya pencegahan penyakit demam berdarah dengue dihabiskan untuk melakukan fogging. ${ }^{16}$ Seperti halnya di Indonesia, sebagian besar masyarakat masih menganggap bahwa fogging merupakan pilihan yang paling tepat untuk melakukan pemberantasan sarang nyamuk. Padahal, fogging merupakan pengendalian vektor secara kimiawi yang penggunaannya seharusnya diminimalkan karena kurang ramah lingkugan. 17 Fogging yang dilakukan dapat meyebabkan pencemaran lingkungan dan juga nyamuk menjadi resistant jika dosis yang digunakan tidak sesuai. Selain itu, seharusnya kegiatan fogging merupakan alternatif yang dilakukan jika keadaan lingkungan sudah darurat karena terjadinya wabah DBD. ${ }^{18}$ Jika belum terjadi wabah DBD maka masyarakat seharusnya melakukan kegiatan pemberantasan sarang nyamuk melalui mengubur, menutup dan menguras bak mandi setiap 1 kali seminggu secara rutin dan serentak pada semua masyarakat. ${ }^{11}$

Pencegahan dan pengendalian vektor di sekolah menjadi tanggung jawab bersama semua pihak yang ada di sekolah. ${ }^{12}$ Seperti sekolah, pondok pesantren, perkantoran dan perusahaan/ industry, lingkungan sekolah dapat menjadi kalompok masyarakat kunci untuk melakukan perubahan per- 
ilaku. Perubahan sikap dan perilaku dalam pencegahan dan pengendalian vektor penyakit menular sangat dibutuhkan untuk melindungi komunitas yang ada di dalamnya dan juga akan bermanfaat untuk komunitas masyarakat di sekitarnya. ${ }^{19}$

Metode SBVC ini memberikan dan mendorong penguatan koordinasi internal komunitas di sekolah akan pentingnya kerjasama dan komunikasi siswa dalam melakukan pemantauan lingkungan untuk mencegah tempat perkembangbiakan vektor. Pencegahan dan pengendalian vektor di sekolahan, pada intinya adalah melibatkan pengurus, guru dan juga siswa untuk turut serta dalam kegiatan pemberantasan vektor penyakit menular. Pengurus/ stake holder di sekolah merupakan orang-orang yang menjadi penentu kebijakan, termasuk kebijakan dalam pengelolaan lingkungan dan penentu dalam memberikan pendidikan kesehatan untuk mendorong mereka berperilaku bersih dan sehat. ${ }^{10,}{ }^{20,21}$ Melalui metode ini siswa mulai dibiasakan dan dididik untuk melakukan perilaku hidup bersih dan sehat dan bekerja sama dengan teman-temannya untuk menciptakan lingkungan sekolah yang sehat. Kesadaran inilah yang diharapkan agar terus terjaga sampai mereka terjun ke masyarakat.

\section{KESIMPULAN DAN SARAN}

Metode SBVC dapat diterapkan dengan sekolah melalui koordinasi guru dan siswa. Selain itu, peran aktif dari siswa menjadi kunci pokok pengendalian dan pemantauan lingkungan yang bebas vektor. Indikator kebersihan perorangan, kebersihan di dalam kelas, kebersihan di jamban dan tempat wudhu, dan kebersihan di halaman sekolah antara sebelum dan setelah diterapkan SBVC meningkat secara signifikan. Jadi, perilaku hidup bersih dan sehat pada siswa dalam mencegah dan mengendalikan vektor di sekolah meningkat signifikan setelah diterapkan SBVC.

Bagi pihak sekolah, diharapkan dapat menyelesaikan masalah kesehatan yang terjadi pada siswa dengan metode SBVC agar masalah kesehatan siswa dapat terselesaikan dengan baik. Penyelesaian yang dilakukan sesuai dengan kemampuan sekolah serta sesuai dengan kebutuhan siswa. Selain itu, pihak pesantren diharapkan dapat memberikan bimbingan dan menyampaikan informasi dengan bekerja sama dengan pihak ter- kait agar siswa semakin sadar akan pentingnya PHBS di sekolah. Bagi siswa, diharapkan mempunyai motivasi diri untuk selalu meningkatkan PHBS dan melakukan manajemen lingkungan untuk mengendalikan dan mencegah vektor penyakit menular di sekolah.

\section{UCAPAN TERIMA KASIH}

Peneliti mengucapkan terima kasih kepada LP2M (Lembaga Penelitian dan Pengabdian Kepada Mesayarakat) Universitas Negeri Semarang yang telah memberikan dana kepada Penulis untuk menjalankan penelitian. Ucapan terima kasih juga ditujukan kepada keluarga SMP Islam Sultan Agung 4 Semarang atas kerjasamanya sehingga penelitian ini dapat terlaksana dengan baik.

\section{DAFTAR PUSTAKA}

1. Azwar S. Sikap Manusia : Teori dan Pengukurannya. Yogyakarta: Pustaka Pelajar; 2006.

2. Kusuma LI. Hubungan antara Trias UKS dengan Pelaksanaan PHBS Pada Murid Di SDN 1 dan 4 Plalangan Gunungpati Semarang 2013 [Skripsi]. Semarang: Udinus; 2013.

3. Badri M. Higiene Perseorangan Santri Pondok Pesantren Wali Songo Ngabar Ponorogo. Media Litbang Kesehatan. 2007;XVII(2):20-7.

4. Kennedy E, Gray N, Azzopardi P, Creati M. Adolescent Fertility and Family Planning in East Asia and The Pacific: a Review of DHS Reports. Reprod Health. 2011;8:11.

5. Muadz MM, Fathonah S, Syarbaini, Mardiana N, Utomo B, Salamah U. Modul dan Kurikulum Pelatihan Pemberian Informasi Kesehatan Reproduksi Remaja oleh Pendidik Sebaya. Jakarta: BKKBN; 2008.

6. Williams, Mullen Stephanie, Karim Ali, Jessica. P. Evaluation of The African Youth Alliance Program in Ghana, Tanzania, and Uganda, Impact on Sexual and Reproductive Health Behavior Among Young People. New York: United Nations Population Fund, UNFPA, Devision A;2007.

7. Notoatmojo S. Pendidikan dan Perilaku Kesehatan. Jakarta: Rineka Cipta; 2007.

8. ADB and WHO. Managing Regional Public Goods for Health, Community-Based Dengue Vector Control. Cambojia: WHO; 2013.

9. Jupatanakul N, Sim S, Dimopoulos G. Aedes 
aegypti ML and Niemann-Pick Type C Family Members are Agonists of Dengue Virus Infection. Developmental \& Comparative Immunology. 2014;43(1):1-9.

10. Mutero CM, Schlodder D, Kabatereine N, Kramer R. Integrated Vector Management for Malaria Control in Uganda: Knowledge, Perceptions and Policy Development. Malaria Journal. [Research Support, Non-U.S. Gov't]. 2012;11(21):1-10.

11. Naranjo SE, Ellsworth PC. Fifty Years of The Integrated Control Concept: Moving the Model and Implementation Forward in Arizona. Pest Management Science. [Historical Article Research Support, Non-U.S. Gov’t Research Support, U.S. Gov't, Non-P.H.S. Review]. 2009 Dec;65(12):1267-86.

12. Van Den Berg H, Von Hildebrand A, Ragunathan V, Das PK. Reducing Vector-Borne Disease by Empowering Farmers in Integrated Vector Management. Bulletin of the World Health Organization. Research Support, NonU.S. Gov’t. 2007 Jul;85(7):561-6.

13. Zhang D, Zheng X, Xi Z, Bourtzis K, Gilles JR. Combining the Sterile Insect Technique With the Incompatible Insect Technique: I-impact of Wolbachia Infection on The Fitness of Triple- and Double-Infected Strains of Aedes Albopictus. PloS one. Research Support, NonU.S. Gov't. 2015;10(4):121-6.

14. Siyam N. Integrated and Comprehensive Action to Reduce and Control Dengue Hemorrhagic Fever: A Survey in Pekalongan City, Central Java. Tropical Medicine Journal. 2013;03 No. 1:85-93.

15. Siyam N. Strengthening of Self Care Management to Improve Clean and Healthy Lifestyle
Habits of Female Santri Efforts as Candidate as Preparation of Mother. 2nd International Seminar on Public Health and Education; 2015; Semarang City: Jurusan IKM Unnes; 2015.

16. Packierisamy PR, Ng CW, Dahlui M, Inbaraj J, Balan VK, Halasa YA, et al. Cost of Dengue Vector Control Activities in Malaysia. The American Journal of Tropical Medicine and Hygiene. Research Support, Non-U.S. Gov't. 2015 Nov;93(5):1020-7.

17. Chanda E, Ameneshewa B, Mihreteab S, Berhane A, Zehaie A, Ghebrat Y, et al. Consolidating Strategic Planning and Operational Frameworks for Integrated Vector Management in Eritrea. Malaria Journal. [Research Support, Non-U.S. Gov't]. 2015;14(1):488.

18. Zhu F, Lavine L, O’Neal S, Lavine M, Foss C, Walsh D. Insecticide Resistance and Management Strategies in Urban Ecosystems. Insects. [Review]. 2016;7(1):1-26.

19. Lizzi KM, Qualls WA, Brown SC, Beier JC. Expanding Integrated Vector Management to Promote Healthy Environments. Trends In Parasitology. [Research Support, N.I.H., Extramural Review]. 2014 Aug;30(8):394-400.

20. Chanda E, Govere JM, Macdonald MB, Lako RL, Haque U, Baba SP, et al. Integrated Vector Management: a Critical Strategy for Combating Vector-Borne Diseases in South Sudan. Malaria Journal. [Research Support, Non-U.S. Gov't Review]. 2013;12(369):1-9.

21. Nalwanga E, Sempebwa JC. Knowledge and Practices of In-Home Pesticide Use: a Community Survey In Uganda. Journal of Environmental and Public Health. 2011;2011:1-7. 